\title{
A 60-Year-Old Man with Cerebral Metastasis of Malignant Melanoma of Left Sole
}

\author{
Abhisak Bhattacharjee ${ }^{1}$, Nabir Hossain ${ }^{2}$ \\ Received: August 22, 2015 Accepted: November 30, 2015 \\ doi: http://dx.doi.og/10.3329/jemc.v6i1.26383
}

\begin{abstract}
A 60-year-old man was diagnosed as a case of malignant melanoma on the left sole and received three cycles of neoadjuvant chemotherapy. Then local excision of the lesion was done. During preoperative diagnostic work-up, there were no features of metastases in lung, liver and bones. On the $3^{\text {rd }}$ postoperative day he presented with right sided hemiparesis. After appearance of neurological features, computed tomography was done and it showed multiple cerebral metastases surrounded by brain edema in both the parietal lobes. The lesions were large, causing increased intracranial pressure. The patient was then referred to the National Institute of Neuroscience (NINS) for further management.
\end{abstract}

Key words: Malignant melanoma; Surgical resection; Multiple metastases

J Enam Med Col 2016; 6(1): 51-54

\section{Introduction}

Cutaneous malignant melanoma is the third most common cause of cerebral metastases in men after lung cancer. ${ }^{1}$ The reported incidence of brain metastases $(\mathrm{BM})$ is $10-40 \%$, but many patients may have subclinical BM, as evidenced by higher reported incidence at autopsy (12-73\%) and the frequent discovery of asymptomatic BM in brain imaging studies. $^{2}$

The natural course of the disease is generally accepted to be variable and unpredictable from patient to patient. Brain metastasis usually occurs within a few years after removal of the primary malignant melanoma although 5-15 years may elapse in some cases. Patients die usually within a few months after the clinical manifestations of BM; however, longer survival has also been reported. ${ }^{3-5}$

Of all primary tumors, it has the highest propensity to metastasize to the brain - up to $75 \%$ of all patients who died from melanoma harbor brain metastasis and in $50 \%$ of these patients, brain metastasis is the cause of death. $^{6-9}$ Neurological death is the common way of termination of life in these patients. Clinical outcome of patients with melanoma with brain metastasis has been dismal, with survival averaging less than six months, notwithstanding standard combined treatment with surgery and radiation therapy. 2,10

Multiple metastases to the brain from malignant melanoma are not uncommon. These tumors are highly vascular and have higher tendency to bleed. ${ }^{1}$ Several studies documented that primary cutaneous malignant melanoma and brain metastasis do not coexist simultaneously. ${ }^{3-5}$ Here we report a case of malignant melanoma of sole who presented with both clinical and radiological evidence of $\mathrm{BM}$.

\section{Case report}

A 60-year-old Hindu farmer hailing from Kishoregonj was admitted into National Institute of Cancer Research \& Hospital (NICRH) with an ulcerated lesion on his left

1. Assistant Registrar, Department of Surgical Oncology, National Institute of Cancer Research and Hospital (NICRH), Mohakhali, Dhaka

2. Junior Consultant, Department of Surgical Oncology, NICRH, Mohakhali, Dhaka

Correspondence Abhisak Bhattacharjee, Email: abhishakdr123@gmail.com 
sole and left sided inguinal lymphadenopathy. The ulcerative lesion was $2 \mathrm{~cm} \times 3 \mathrm{~cm}$ in size, blackish in color, surrounded by multiple satellite nodules with irregular surface and margins (Fig 1). The edges were everted, floor was covered by unhealthy slough with blackish tissue debris. The lesion was non-tender, local temperature was normal and the base was indurated but the lesion was free from the underlying bone. No intransit deposits were found. Excision biopsy was done and histopathology showed poorly differentiated malignant tumor. The left inguinal lymph nodes were enlarged, multiple in numbers, hard and fixed with one another as well as fixed with overlying skin but free from underlying structures. FNAC was consistent with the features of metastatic malignant melanoma (Fig 2). The patient had no features suggestive of hepatic, pulmonary, bony and cerebral metastases.

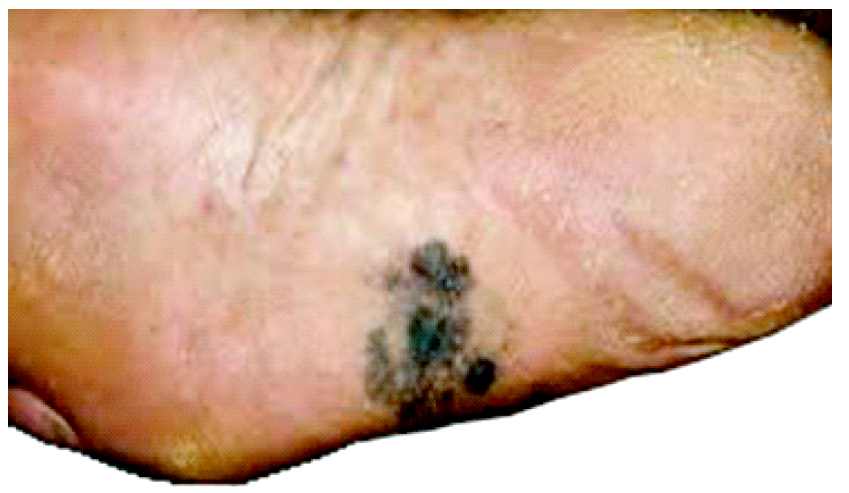

Fig 1. Malignant melanoma with surrounding satellite nodules

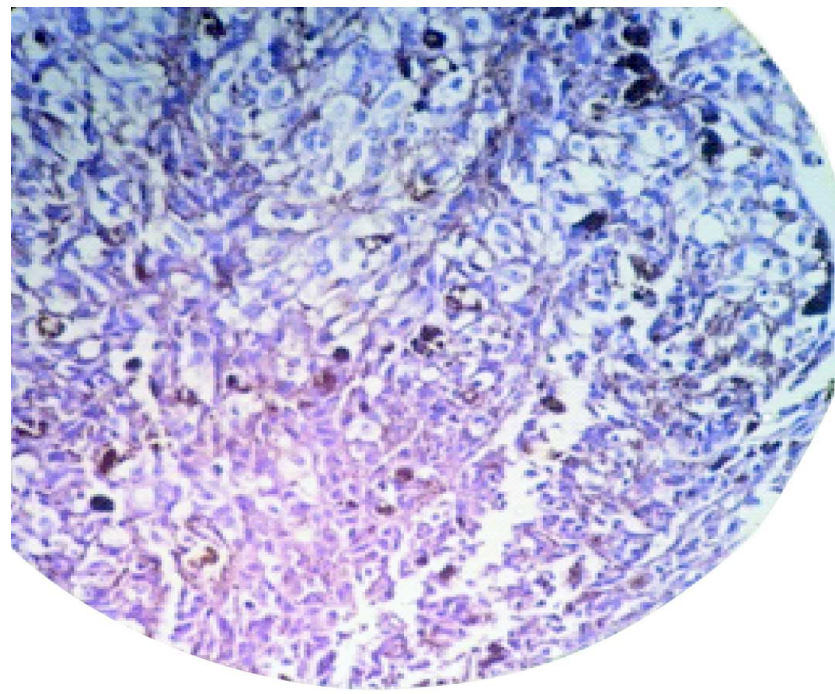

Fig 2. Histopathology of malignant melanoma
The patient received 3 cycles of chemotherapy combination of cisplatin and dacarbazine (DTIC). All parameters were thoroughly assessed. Radiography of the left foot showed no bony involvement, the ultrasound of abdomen revealed normal findings and chest radiography showed no sign of metastasis. All routine biochemical parameters were within normal limit. The patient was then referred to the surgical oncology unit for intervention.

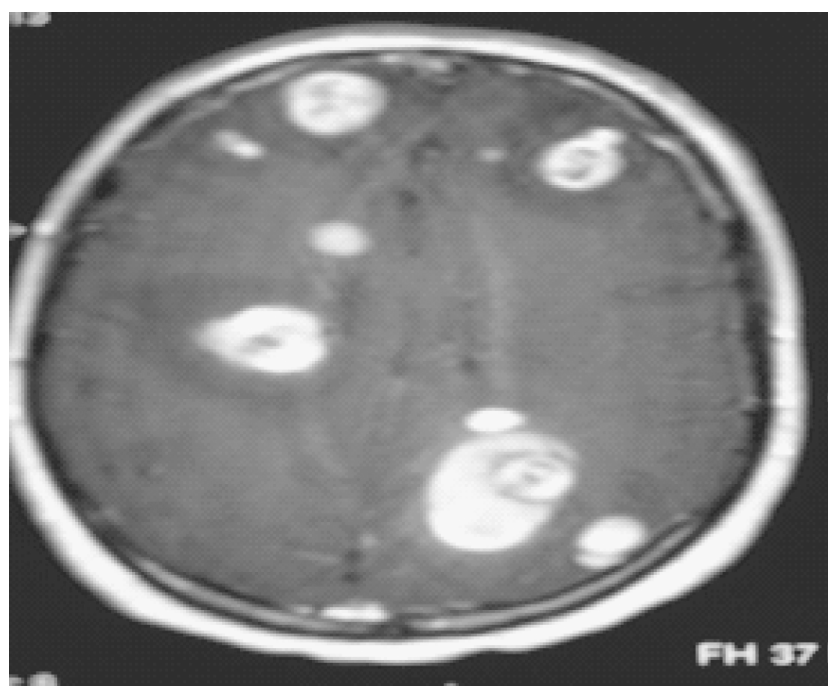

Fig 3. Bilateral multiple cerebral metastases in CT scan of brain

After adequate pre-operative work-up wide local excision of the primary lesion and inguinal lymph node dissection of the ipsilateral side were done. The postoperative outcome was uneventful up to the $3^{\text {rd }}$ postoperative day. Then the patient suddenly developed right sided hemiparesis. On examination, Glasgow Coma Scale (GCS) was 15, the Modified Research Council (MRC) muscle strength was $3 / 5$, the bowel and bladder control were intact. CT scan of brain was done and bilateral cerebral metastases were found (Fig 3). The patient was then referred to National Institute of Neuroscience (NINS) for further management.

\section{Discussion}

Melanomas are the third most common cause of intracranial metastases after breast and lung carcinomas. ${ }^{11,12}$ The incidence of central nervous system (CNS) metastases in patients with melanomas ranges from $10-40 \%$ in clinical studies. ${ }^{13} \mathrm{CNS}$ metastasis is the most worrisome feature of malignant 
melanoma, leading directly to death in the majority of patients. ${ }^{9,14}$ The central nervous system acts as a sanctuary site for metastases. This may be because of the relatively impermeable blood-brain barrier to chemotherapeutic agents, therefore explaining the disappointing results with cisplatin, fotemustine, lomustine and dacarbazine. ${ }^{14}$

A standard treatment for patients with metastatic malignant melanoma has not been yet established. The prognosis of cerebral metastasis of malignant melanoma is poor. The median survival time ranges between $2-10$ months. ${ }^{15-21}$ Only $10 \%$ of patients survive more than 1 year after diagnosis. ${ }^{22}$ The therapeutic response of patients strongly depends on the number of metastases. ${ }^{2,21-23} \mathrm{Age}$, sex and the time interval between the period of appearance of primary malignant melanoma manifestations and the features of cerebral metastasis have not shown any significant effect on the clinical outcome. ${ }^{21}$

Frequently multiple cerebral metastases are evident. $^{23,24}$ Prospective randomized trials have demonstrated the benefit of surgery for the treatment of a single metastasis in the brain. ${ }^{25}$ So, surgery is the choice of treatment for the majority of patients with a single metastatic lesion ${ }^{26}$, but only a few selected patients with multiple metastases in the brain are treated surgically. ${ }^{27}$

Recently, Konstadoulakis et $\mathrm{al}^{27}$ reported that the median survival time of surgical resection for multiple brain metastases was 8 months. They concluded that performing multiple resections of brain metastases from melanoma is considered as a radical approach, especially in young patients with well-controlled systemic disease. The main aim of a simultaneous onestage resection for multiple metastatic lesions is limited improvement in the quality of the patient's remaining life, so the indications are extremely limited. The two preconditions required are - the patients should be young and have well-controlled systemic disease, and dramatic improvements of neurological symptoms may be expected following the resections.

The surgical options for managing two intracranial lesions are influenced by the presence of another intracranial tumor. When two lesions are contiguous, they may usually be removed using a single approach, but when they are distant from each other, the surgical approach depends upon the type of lesions. ${ }^{28}$ When one tumor is malignant and the other is benign, the malignant tumor must be removed first. A second craniotomy may be performed at least 10 to 12 months later when the benign tumor is large enough and/or symptomatic, or shows a tendency to grow. When the two lesions are malignant and large or symptomatic tumors, both lesions may require early resection. In such cases, there is no consensus as to the best surgical management. In the present case, the patient presented with multiple large distant symptomatic metastatic lesions. The one-stage operation using two approaches has several risks. The patient's surgical position must be changed under general anesthesia and the operation time is longer and more invasive. Nevertheless, the significant reduction of intracranial pressure obtained by surgery may produce immediate and dramatic improvements of the patient's neurological symptoms. The conventional treatment for multiple metastatic brain tumors is radiotherapy. ${ }^{29}$ The superiority of surgical treatment over radiotherapy for managing multiple metastases in brain from primary malignancy is nothing but the immediate reduction of intracranial pressure.

\section{References}

1. American brain tumor association. Available at: http://www.abta.org/secure/metastatic-brain-tumor.pdf. Accessed April 2015.

2. Sampson JH, Carter JH Jr, Friedman AH, Seigler HF. Demographics, prognosis and therapy in 702 patients with brain metastases from malignant melanoma. J Neurosurg 1998; 88: 11-20.

3. Bauman ML, Price TR. Intracranial metastatic malignant melanoma: long term survival following subtotal resection. South Med J 1972; 65: 344-346.

4. Kiel FW, Starr LB, Hansen JL. Primary melanoma of the spinal cord. J Neurol 1961; 18: 616-621.

5. Lin T, Cook AW. Primary melanoma within the spinal canal. N Y St Med 1966; 663: 1914-1916.

6. Vieth RG, Odom GL. Intracranial metastases and their neurosurgical treatment. J Neurosurg 1965; 23: 375-383.

7. Amer MH, Al-Sarraf M, Baker LH, Vaitkevicius VK. Malignant melanoma and central nervous system metastases: incidence, diagnosis, treatment and survival. Cancer 1978; 42: 660-668.

8. Barnholtz-Sloan JS, Sloan AE, Davis FG, Vigneau FD, Lai P, Sawaya RE. Incidence proportions of brain metastases in patients diagnosed (1973 to 2001) in the Metropolitan 
Detroit Cancer Surveillance System. J Clin Oncol 2004; 22: 2865-2872.

9. Budman DR, Camacho E, Wittes RE. The current causes of death in patients with malignant melanoma. Eur J Cancer 1978; 14: 327-330.

10. Hofmann MA, Coll SH, Kuchler I, Kiecker F, Wurm R, Sterry W. Prognostic factors and impact of treatment in melanoma brain metastases: better prognosis for women? Dermatology 2007; 215: 10-16.

11. Kingdom TT, Lalwani AK, Pitts LH. Isolated metastatic melanoma of the cerebellopontine angle: case report. Neurosurgery 1993; 33: 142-144.

12. Morita A, Meyer FB, Laws ER Jr. Symptomatic pituitary metastases. J Neurosurg 1998; 89: 69-73.

13. Amer MH, Al-Sarraf M, Vaitkevicius VK. Clinical presentation, natural history and prognostic factors in advanced malignant melanoma. Surg Gynecol Obstet 1979; 149: 687-692.

14. Gupta G, Robertson AG, Mackie RM. Cerebral metastases of cutaneous melanoma. British Journal of Cancer 1997; 76(2): 256-259.

15. Ferraresi V, Ciccarese M, Zeuli M, Cognetti F. Central nervous system as exclusive site of disease in patients with melanoma: treatment and clinical outcome of two cases. Melanoma Res 2005; 15: 467-469.

16. Fife KM, Colman MH, Stevens GN, Firth IC, Moon D, Shannon KF. Determinants of outcome in melanoma patients with cerebral metastases. J Clin Oncol 2004; 22: 1293-1300.

17. Hofmann M, Kiecker F, Wurm R, Schlenger L, Budach V, Sterry W. Temozolomide with or without radiotherapy in melanoma with unresectable brain metastases. J Neurooncol 2006; 76: 59-64.

18. Petrovich Z, Yu C, Giannotta SL, O’Day S, Apuzzo ML. Survival and pattern of failure in brain metastasis treated with stereotactic gamma knife radiosurgery. J Neurosurg 2002; 97: 499-506.

19. Retsas S, Gershuny AR. Central nervous system involvement in malignant melanoma. Cancer 1988; 61: 1926-1934.
20. Fernandez E, Maira G, Puca A, Vignati A. Multiple intracranial metastases of malignant melanoma with longterm survival. Case report. J Neurosurg 1984; 60: 621-624.

21. Zacest AC, Besser M, Stevens G, Thompson JF, McCarthy WH, Culjak G. Surgical management of cerebral metastases from melanoma: outcome in 147 patients treated at a single institution over two decades. J Neurosurg 2002; 96: 552-558.

22. Somaza S, Kondziolka D, Lunsford LD, Kirkwood JM, Flickinger JC. Stereotactic radiosurgery for cerebral metastatic melanoma. J Neurosurg 1993; 79: 661-666.

23. Stevens G, Firth I, Coates A. Cerebral metastases from malignant melanoma. Radiother Oncol 1992; 23: 185-191.

24. Wronski M, Arbit E. Surgical treatment of brain metastases from melanoma: a retrospective study of 91 patients. J Neurosurg 2000; 93: 9-18.

25. Noordijk EM, Vecht CJ, Haaxma-Reiche H, Padberg GW, Voormolen JH, Hoekstra FH. The choice of treatment of single brain metastasis should be based on extracranial tumor activity and age. Int J Radiat Oncol Biol Phys 1994; 29: 711-717.

26. Salvati M, Frati A, D’Elia A, Pescatori L, Piccirilli M, Pietrantonio A. Single brain metastases from melanoma: remarks on a series of 84 patients. Neurosurg Rev 2011; 14.

27. Konstadoulakis MM, Messaris E, Zografos G, Androulakis G, Karakousis C. Prognostic factors in malignant melanoma patients with solitary or multiple brain metastases. Is there a role for surgery? J Neurosurg Sci 2000; 44: 211-218.

28. Maiuri F, Cappabianca P, Iaconetta G, Esposito F, Messina A. Simultaneous presentation of meningiomas with other intracranial tumours. Br J Neurosurg 2005; 19: 368-375.

29. Assouline A, Levy A, Chargari C, Lamproglou I, Mazeron JJ, Krzisch C. Whole brain radiotherapy: prognostic factors and results of a radiation boost delivered through a conventional linear accelerator. Radiother Oncol 2011; 99: 214-217. 